This article is licensed under the Creative Commons Attribution-NonCommercial 4.0 International License (CC BY-NC) (http://www.karger.com/Services/OpenAccessLicense). Usage and distribution for commercial purposes requires written permission.

\title{
Pneumoperitoneum after Endoscopic Retrograde Cholangiopancreatography due to Rupture of Intrahepatic Bile Ducts and Glisson's Capsule in Hepatic Metastasis: A Case Report and Review of Literature
}

\author{
Zubair Khan ${ }^{a} \quad$ Umar Darr $^{\mathrm{a}} \quad$ Mohamad Nawras $^{\mathrm{a}} \quad$ Muhammad Bawany $^{\mathrm{a}}$ b \\ Jacob Bieszczad ${ }^{c}$ Osama Alaradi ${ }^{a, b} \quad$ Ali Nawras ${ }^{a, b}$ \\ aUniversity of Toledo Medical Center, Department of Internal Medicine, Toledo, OH, USA; \\ ${ }^{\mathrm{b}}$ Division of Gastroenterology, University of Toledo, Toledo, OH, USA; \\ 'University of Toledo Medical Center, Department of Radiology, Toledo, OH, USA
}

\section{Keywords}

Endoscopic retrograde cholangiopancreatography $\cdot$ Pneumoperitoneum $\cdot$ Hepatic metastasis

\begin{abstract}
Introduction: Endoscopic retrograde cholangiopancreatography (ERCP) has been proven to be a safe and effective method for diagnosis and treatment of biliary and pancreatic disorders. Major complications of ERCP include pancreatitis, hemorrhage, cholangitis, and duodenal perforation. We report a third case in literature of pneumoperitoneum after ERCP due to rupture of intrahepatic bile ducts and Glisson's capsule in a peripheral hepatic lesion. Case
\end{abstract}




\section{Case Reports in Gastroenterology}

Case Rep Gastroenterol 2017;11:603-609

(c) 2017 The Author(s). Published by S. Karger AG, Basel www.karger.com/crg

Khan et al:: Pneumoperitoneum after Endoscopic Retrograde Cholangiopancreatography due to Rupture of Intrahepatic Bile Ducts and Glisson's Capsule in Hepatic Metastasis

Report: A 50-year-old male with a history of metastatic pancreatic neuroendocrine tumor and who had a partially covered metallic stent placed in the biliary tree 1 year ago presented to the oncology clinic with fatigue, abdominal pain, and hypotension. He was planned for ERCP for possible cholangitis secondary to obstructed previously placed biliary stent. However, the duodenoscope could not be advanced to the level of the major papilla because of narrowed pylorus and severely strictured duodenal sweep. Forward-view gastroscope was then passed with careful manipulation to the severely narrowed second part of the duodenum where the previously placed metallic stent was visualized. Balloon sweeping of stenting was done. Cholangiography did not show any leak. Following the procedure, the patient underwent $\mathrm{CT}$ scan of the abdomen that showed pneumoperitoneum which was communicating with pneumobilia through a loculated air collection in necrotic hepatic metastasis perforating Glisson's capsule. The patient was managed conservatively. Conclusion: In our case, pneumoperitoneum resulted from rupture of intrahepatic bile ducts and Glisson's capsule in hepatic metastasis. This case emphasizes the need for close clinical and radiological observation of patients with hepatic masses (primary or metastatic) subjected to ERCP.

(C) 2017 The Author(s)

Published by S. Karger AG, Basel

\section{Introduction}

Endoscopic retrograde cholangiopancreatography (ERCP) has been in clinical practice for more than 50 years. Initially used only for diagnostic purposes, it is now the main diagnostic and therapeutic modality for biliary and pancreatic pathologies because of lower morbidity and mortality than surgery [1]. It is even a safer procedure in octogenarians with low risk of complications despite having multiple comorbid conditions [2,3].

Major complications of ERCP include pancreatitis, hemorrhage, cholangitis, and duodenal perforation $[4,5]$. The most concerning of these complications is perforation. All endoscopic procedures can cause intestinal perforation; however, use of side-viewing endoscopes and additional procedures, such as sphincterotomy, increase this risk during ERCP [6]. We report a rare case of post-ERCP pneumoperitoneum due to air leakage from rupture of intrahepatic bile ducts and Glisson's capsule in a hepatic metastasis.

\section{Case Report}

A 50-year-old male with a history of metastatic pancreatic neuroendocrine tumor, who has received chemotherapy and radiation in the past and had a partially covered metallic stent placed in the biliary tree 1 year ago, presented to the oncology clinic with fatigue, abdominal pain, and hypotension. He was found to have elevated bilirubin of $9.7 \mathrm{mg} / \mathrm{dL}$, and alkaline phosphatase was slightly elevated at $162 \mathrm{IU} / \mathrm{L}$. AST and ALT were within normal limits. CBC showed WBC count of $14.8 \times 10^{3} / \mathrm{mm}^{3}$, segments were $93 \%$. He underwent ERCP for possible cholangitis secondary to obstructed previously placed biliary stent.

However, the duodenoscope could not be advanced to the level of major papilla because of narrowed pylorus and severely strictured duodenal sweep and second part of the duode- 


\section{Case Reports in \\ Gastroenterology}

Case Rep Gastroenterol 2017;11:603-609

(c) 2017 The Author(s). Published by S. Karger AG, Basel www.karger.com/crg

Khan et al: Pneumoperitoneum after Endoscopic Retrograde Cholangiopancreatography due to Rupture of Intrahepatic Bile Ducts and Glisson's Capsule in Hepatic Metastasis

num. Forward-view gastroscope was then passed with careful manipulation to the severely narrowed second part of the duodenum where the previously placed metallic stent was visualized. Attempts made to cannulate the common bile duct through the metallic stent using the forward-view gastroscope were eventually successful and the balloon sweeping through the stent was done with removal of sludge. Cholangiography after balloon sweep showed there was no contrast leakage through the common bile duct.

Patient did not have any abdominal pain but nausea after the procedure. He was afebrile and hemodynamically stable and on physical exam, the abdomen was soft with mild right hypochondrial tenderness, and the bowel sounds were audible. His WBC count was $10.8 \times$ $10^{3} / \mathrm{mm}^{3}$ and the bilirubin was $6.9 \mathrm{mg} / \mathrm{dL}$ the next day. He was kept NPO till the results of further workup.

Patient underwent CT scan of the abdomen after ERCP to look at the biliary channels and the progression of malignancy. CT scan of the abdomen beside demonstrating pancreatic tumor and diffuse hepatic metastasis showed pneumoperitoneum which was communicating with the pneumobilia through a loculated air collection in the right lobe of liver (necrotic hepatic metastasis) perforating Glisson's capsule (Fig. 1, Fig. 2). CT scan of the abdomen did not show pneumoretroperitoneum and subsequent upper gastrointestinal tract study with contrast did not show any duodenal perforation (Fig. 3). The patient was managed conservatively via NG tube placement, i.v. fluids and i.v. antibiotics. Repeat CT scan in 1 week showed resolving pneumoperitoneum with conservative treatment only. The patient was discharged on day 10 of ERCP.

\section{Discussion}

The incidence of ductal and duodenal perforation post-ERCP is very rare (1\%). Most of these perforations are retroperitoneal (80\%) leading to pneumoretroperitoneum. Hence, pneumoperitoneum during or after ERCP is an even rarer occurrence [4].

In this case after ERCP, the subsequent CT scan of the abdomen and the upper gastrointestinal tract study with contrast did not shown any duodenal perforation, and the cholangiogram after balloon sweeping of the stent did not show any ductal perforation, thus ruling out both duodenal and ductal perforation, respectively. The abdominal CT also revealed a large necrotic air-containing lesion in hepatic metastasis touching Glisson's capsule, and adjacent air in peritoneum suggesting air leak form Glisson's capsule. Thus, bowel distension during ERCP led to pneumobilia, and rupture of bile ducts of liver metastasis owing to friability with subsequent touching and rupture of Glisson's capsule led to pneumperitoneum.

Our case is the third reported case of pneumoperitoneum after ERCP due to rupture of hepatic lesion and Glisson's capsule (Table 1). The first case by Assimakopoulos et al. [7] was of an 84-year-old lady with the history of carcinoma of head of pancreas metastatic to lungs and liver, who had biliary stent placed 2 months back for obstructive jaundice and presented with icterus. The patient underwent ERCP with a stent placed inside the previously placed stent and the subsequent CT scan showed pneumoperitoneum. The second case described by Boškoski et al. [8] was of a 74-year-old gentleman who presented with acute cholangitis as he did not return for his biliary stent exchange that he was having for biliary duct stricture due to chronic pancreatitis. ERCP was performed, which showed stent migration with 
stones above the stricture. The stones were extracted via Dormia basket and a partially covered metallic stent was placed. He was found to have a pneumoperitoneum subsequently from rupture of hepatic abscess in the 3rd hepatic segment.

Both the surgical and conservative strategies are there for management of duodenal perforation leading to pneumoperitoneum [9-12]. No data is available for the management of post-ERCP pneumoperitoneum in the setting of ruptured hepatic lesions adjacent to Glisson's capsule except for our case and the two other cases. Recently, Bray et al. [6] have devised a new classification of ERCP perforations without peritonitis consisting of 4 classes with treatment recommendations that focuses on early antibiotic administration in class I and II and surgery for class III and IV. Here it is important to note that class III and IV is perforation with retroperitoneal fluid and intraperitoneal air, respectively. It does not give any recommendation about the cases with only pneumoperitoneum without retroperitoneal fluid or air due to rupture of hepatic lesions and Glisson's capsule. But based on literature review of such cases and the significant comorbid conditions, we recommend conservative management.

In conclusion, we are reporting a third case of pneumoperitoneum in the literature after ERCP because of rupture of intrahepatic bile ducts in hepatic metastasis and Glisson's capsule. Based on our case and the review of other two cases, we recommend close monitoring of patients having peripheral hepatic metastasis or primary hepatocellular carcinoma or hepatic abscess. Also, avoidance of excessive air insufflation and immediate decompression of gastrointestinal tract via nasogastric tube after procedure can be helpful in prevention. We recommend conservative management in these cases.

\section{Statement of Ethics}

The authors have no ethical conflicts to disclose.

\section{Disclosure Statement}

The authors have no conflicts of interest to disclose.

\section{Author Contributions}

Zubair Khan and Umar Darr contributed equally in writing the case report manuscript and major parts of discussion. Mohamad Nawras and Muhammad Bawany assisted in the literature review. Jacob Bieszczad reviewed and labelled the radiological images. Osama Alaradi and Ali Nawras supervised and reviewed the entire article. 


\section{Case Reports in Gastroenterology}

Case Rep Gastroenterol 2017;11:603-609

DOI: $10.1159 / 000481163$

www.karger.com/crg

Khan et al.: Pneumoperitoneum after Endoscopic Retrograde Cholangiopancreatography due to Rupture of Intrahepatic Bile Ducts and Glisson's Capsule in Hepatic Metastasis

\section{References}

1 Carr-Locke DL: Therapeutic role of ERCP in the management of suspected common bile duct stones. Gastrointest Endosc 2002;56:S170-S174.

2 Koklu S, Parlak E, Yuksel O, Sahin B: Endoscopic retrograde cholangiopancreatography in the elderly: a prospective and comparative study. Age Ageing 2005;34:572-577.

-3 Thomopoulos KC, Vagenas K, Assimakopoulos SF, Giannikoulis C, Arvaniti V, Pagoni N, Nikolopoulou VN: Endoscopic retrogade cholangiopancreatography is safe and effective method for diagnosis and treatment of biliary and pancreatic disorders in octogenarians. Acta Gastroenterol Belg 2007;70:199_ 202.

4 Loperfido S, Angelini G, Benedetti G, Chilovi F, Costan F, De Berardinis F, De Bernardin M, Ederle A, Fina P, Fratton A: Major early complications from diagnostic and therapeutic ERCP: a prospective multicenter study. Gastrointest Endosc 1998;48:1-10.

5 Salminen P, Laine S, Gullichsen R: Severe and fatal complications after ERCP: analysis of 2,555 procedures in a single experienced center. Surg Endosc 2008;22:1965-1970.

-6 Bray MS, Borgert AJ, Folkers ME, Kothari SN: Outcome and management of endoscopic retrograde cholangiopancreatography perforations: a community perspective. Am J Surg 2017;214:69-73.

-7 Assimakopoulos SF, Thomopoulos KC, Giali S, et al: A rare etiology of postendoscopic retrograde cholangiopancreatography pneumoperitoneum. World J Gastroenterol 2008;14:2917-2919.

-8 Boškoski I, Tringali A, Familiari P, Costamagna G: An unusual post-ERCP pneumoperitoneum. Dig Liver Dis 2011;43:579.

-9 Sarr MG, Fishman EK, Milligan FD, Siegelman SS, Cameron JL: Pancreatitis or duodenal perforation after peri-Vaterian therapeutic endoscopic procedures: diagnosis, differentiation, and management. Surgery 1986;100:461-466.

10 Bell RC, Van Stiegmann G, Goff J, Reveille M, Norton L, Pearlman NW: Decision for surgical management of perforation following endoscopic sphincterotomy. Am Surg 1991;57:237-240.

11 Martin DF, Tweedle DE: Retroperitoneal perforation during ERCP and endoscopic sphincterotomy: causes, clinical features and management. Endoscopy 1990;22:174-175.

12 Scarlett PY, Falk GL: The management of perforation of the duodenum following endoscopic sphincterotomy: a proposal for selective therapy. Aust NZ J Surg 1994;64:843-846. 


\section{Case Reports in Gastroenterology}

Case Rep Gastroenterol 2017;11:603-609

DOI: $10.1159 / 000481163$

(C) 2017 The Author(s). Published by S. Karger AG, Basel www.karger.com/crg

Khan et al.: Pneumoperitoneum after Endoscopic Retrograde Cholangiopancreatography due to Rupture of Intrahepatic Bile Ducts and Glisson's Capsule in Hepatic Metastasis

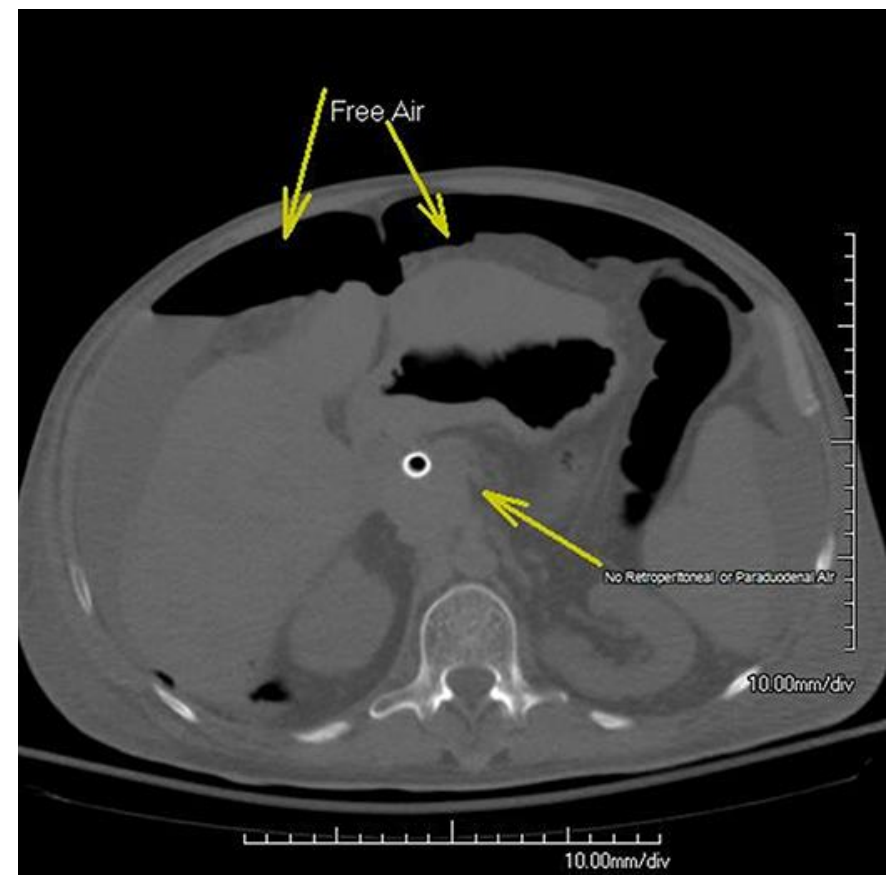

Fig. 1. Axial CT showing free air but no retroperitoneal or paraduodenal air.

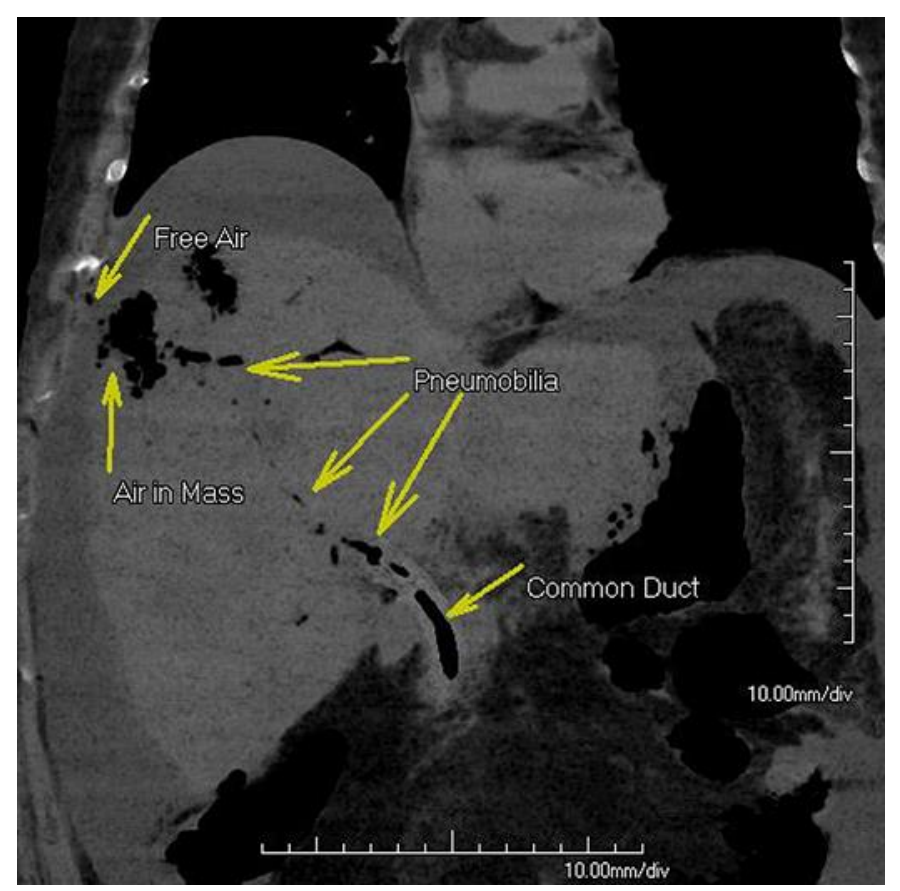

Fig. 2. Coronal view showing pneumobilia with air in mass and adjacent free air. 


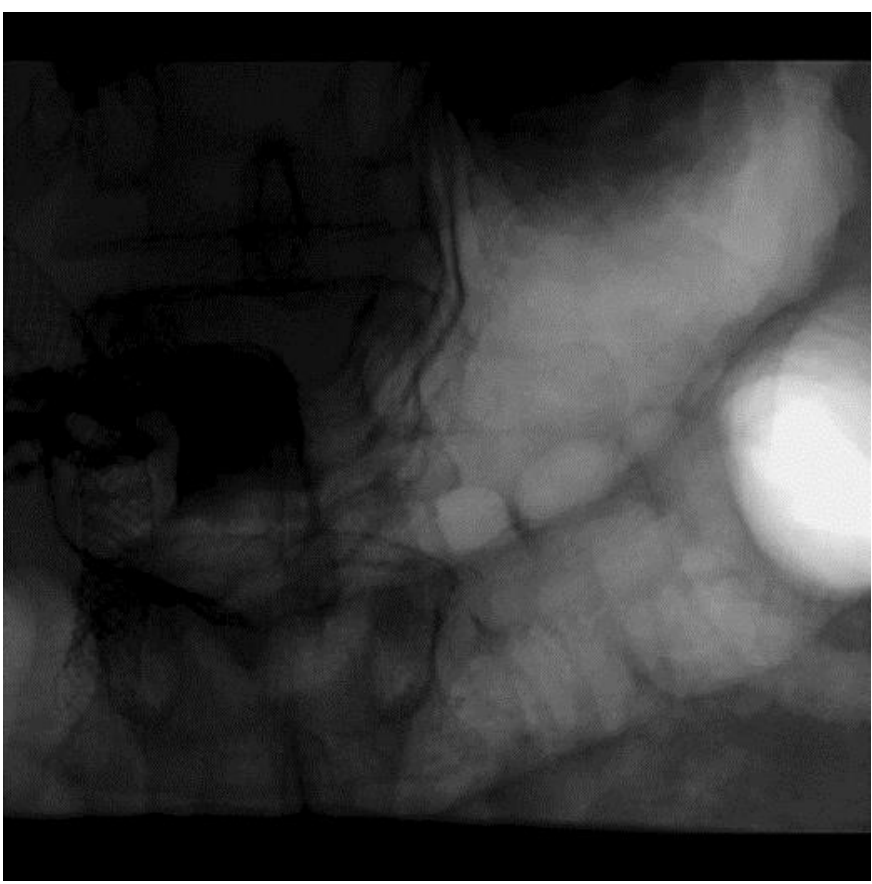

Fig. 3. Upper gastrointestinal tract with no contrast extravasation.

Table 1. Cases of pneumoperitoneum due to rupture of intrahepatic biliary ducts in hepatic lesions adjacent to Glisson's capsule

\begin{tabular}{|c|c|c|c|c|c|c|c|}
\hline Ref & $\begin{array}{l}\text { Age, } \\
\text { years/ } \\
\text { gender }\end{array}$ & Presentation & $\begin{array}{l}\text { Hepatic le- } \\
\text { sions }\end{array}$ & $\begin{array}{l}\text { Primary } \\
\text { malignancy }\end{array}$ & $\begin{array}{l}\text { Symptoms } \\
\text { post ERCP }\end{array}$ & Management & $\begin{array}{l}\text { Recovery } \\
\text { time }\end{array}$ \\
\hline $\begin{array}{l}\text { Assimakopoulos et } \\
\text { al. [7] }\end{array}$ & $84 / \mathrm{F}$ & $\begin{array}{l}\text { Obstructive } \\
\text { jaundice }\end{array}$ & $\begin{array}{l}\text { Hepatic metas- } \\
\text { tasis (right } \\
\text { lobe) }\end{array}$ & $\begin{array}{l}\text { Carcinoma } \\
\text { head of pan- } \\
\text { creas }\end{array}$ & $\begin{array}{l}\text { Abdominal } \\
\text { distension }\end{array}$ & $\begin{array}{l}\text { Conservative (NPO, } \\
\text { NG, i.v. fluids and i.v. } \\
\text { antibiotics) }\end{array}$ & 14 days \\
\hline Boškoski et al. [8] & $74 / \mathrm{M}$ & $\begin{array}{l}\text { Acute cholangi- } \\
\text { tis and septic } \\
\text { shock }\end{array}$ & $\begin{array}{l}\text { Hepatic ab- } \\
\text { scess (left } \\
\text { lobe) }\end{array}$ & None & $\begin{array}{l}\text { None (radio- } \\
\text { logical finding) }\end{array}$ & $\begin{array}{l}\text { Conservative (NPO, } \\
\text { NG, i.v. fluids and i.v. } \\
\text { antibiotics) and } \\
\text { abscess drainage }\end{array}$ & 20 days \\
\hline Present case & $50 / \mathrm{M}$ & $\begin{array}{l}\text { Acute cholangi- } \\
\text { tis and septic } \\
\text { shock }\end{array}$ & $\begin{array}{l}\text { Hepatic metas- } \\
\text { tasis (right } \\
\text { lobe) }\end{array}$ & $\begin{array}{l}\text { Pancreatic } \\
\text { neuro- } \\
\text { endocrine } \\
\text { tumor }\end{array}$ & $\begin{array}{l}\text { None (radio- } \\
\text { logical finding) }\end{array}$ & $\begin{array}{l}\text { Conservative (NPO, } \\
\text { NG, i.v. fluids and i.v. } \\
\text { antibiotics) }\end{array}$ & 10 days \\
\hline
\end{tabular}

